\title{
EL COLONIALISMO Y LA DOCTRINA DE LA PROPIEDAD DE LOCKE
}

Barbara Arneil*

\section{Resumen}

\section{La obra Two Treatises of Government}

de John Locke ha sido reconocida durante mucho tiempo como un pequeño artículo que formula preguntas que emergen de los acontecimientos políticos nacionales de Inglaterra durante la Restauración. Sin embargo, se han ignorado sus desarrollos políticos en el extranjero, especialmente en la colonización de América. Mientras que Locke y su mecenas, el Conde de Shaftesbury, estaban comprometidos con el desarrollo de la política colonial a través de su obra tanto entre los Propietarios terratenientes de Carolina como entre el Consejo de comercio y plantaciones, la oposición en Inglaterra durante 1670 respecto a la colonización del nuevo mundo era escandalosa. Muchos debatían que Inglaterra no tenía derecho a adueñarse de la tierra que ya estaba ocupada por otros, es decir, los indios americanos. A modo de respuesta, colonizadores como John Winthrop, Robert Cushman y Robert Gray, entre otros, escribieron tratados que defendian el derecho de Inglaterra de establecerse en América. En esencia, argumentaban que la voluntad de Dios era que la tierra estuviera a disposición de aquellos

* Departamento de Ciencias Políticas, British Columbia University, Vancouver. 
BARBARA ARNEIL

que la cercaran y cultivaran pacíficamente sin perjudicar a nadie. Locke incorpora estos argumentos en sus capítulos sobre la propiedad y la conquista en el Segundo tratado, pero los transforma en una teoría que se basa en el derecho natural más que en el teológico. Por lo tanto, en el Segundo tratado las referencias repetidas de Locke a América y a sus habitantes hacen evidente que en sus teorías sobre la propiedad y conquista se incrusta una defensa vigorosa de las actividades coloniales de Inglaterra en el nuevo mundo.

El papel que América ha desempeñado ha sido inadvertido en la erudición de los Dos tratados de gobierno de Locke. ${ }^{1}$ Aunque desde hace mucho tiempo se ha reconocido el peso sobre los asuntos de política nacional en las teorías que Locke desarrolló sobre la propiedad y los derechos naturales, se ha puesto poca atención a la importancia de la política exterior, en especial en lo referente a la colonización de América para el desarrollo de estos temas. ${ }^{2}$ Esta contradicción es sor-

' Una obra reciente ha comenzado a reparar esta brecha en la erudición Lockeana. James Tully ha publicado "Placing the "Two Treatises", Political Discourse in Early Modern Britain, 1993, Cambridge, Nicholas Phillipson and Quentin Skinner (eds.); An Approach to Political Philosophy: Locke in Contexts, 1993, Cambridge; ver también, Thomas Flanagan, "The Agricultural Argument and Original Appropriation: Indian Lands and Political Philosophy", Canadian Journal of Political Science, XXII, 1989; Herman Lebovics, "The Uses of America in Locke's Second Treatise of Government", Journal of the History of Ideas, XLVII, 47, 1986; James Tully, "Discovering America", Main Paper II, The John Locke Conference, September 5-7, 1990 , Oxford.

${ }^{2}$ La discusión sobre el contexto político nacional se revisa más recientemente en David Wootton, "Revolutionary Politics de John Locke y Richard Ashcraft" y en la respuesta de Ashcraft, "Simple Objections and Complex Reality: Theorizing Political Radicalism in Seventeenth Century England", en Political Studies, XL, 1, 1992. Ver también, Peter Laslett, "Locke and the First Earl of Shaftesbury", Mind, $\mathrm{n}^{\circ}$ 241, January, 1952; Richard Ashcraft, Revolutionary Politics and Locke's Two Treatises of Government, 1986, Princeton; David McNally, "Locke, Levellers and Liberty: Property and 
prendente debido al número de referencias específicas que Locke hace sobre América en su obra Two Treatises y la gran participación que tuvo a través de su mecenas, el Conde de Shaftesbury, en el desarrollo de las política sobre las colonias.

Como secretario de los Propietarios terratenientes de Carolina (16681675) y del Consejo de comercio y plantaciones (1673-1675), Locke se adentró en los asuntos coloniales de su tiempo y estuvo al tanto de que el público inglés para el cual escribió fuera muy escéptico respecto de los asentamientos de Inglaterra en el nuevo mundo. Algunos de los opositores a la colonización, particularmente los religiosos puritanos en América, argüían que Inglaterra estaba ocupando tierras que ya estaban habitadas por otras personas: los amerindios. ${ }^{3}$

\section{John Locke y el colonialismo}

Antes de analizar los motivos específicos utilizados por los colonialistas y Locke en la obra Two Treatises, merece la pena considerar el grado de participación que tuvo en los asuntos que emergieron de la colonización de América. La evidencia de la familiaridad de Locke con los asuntos coloniales se encuentra en la colección de libros sobre los temas de comercio y viajes en las Américas, que escribió para varios cuerpos coloniales, y su correspondencia en la década de 1670 con los colonialistas de América sobre el tema de "los nativos".

En la compilación de libros de su biblioteca se enumeran 195 títulos clasificados bajo la categoría de viajes y expediciones, que en su ma-

Democracy in the Thought of the First Whigs", History of Political Thought, X, 1989; G. J. Schochet, 'Radical Politics and Ashcraft's Treatise on Locke', Journal of the History of Ideas, L, 1989.

${ }^{3}$ Hay un problema terminológico con respecto a los pueblos aborígenes de las Américas. El uso del término 'indio' para describir a los miembros de más de 800 naciones, podría ofender a alguien por inapropiado. Decidí utilizar 'amerindio' y 'pueblos aborígenes', términos utilizados en los Estados Unidos y Canadá respectivamente. 
BARBARA ARNEIL

yoría describen viajes a las Américas realizados por exploradores europeos. Ejemplos de obras de esta compilación citadas en Two Treatises son la Historia natural y moral de las Indias de Joseph D'Acosta y los Comentarios reales de Garcilaso de la Vega. ${ }^{4} \mathrm{El}$ interés de Locke en el nuevo mundo se reflejó también en la compilación de libros y sus anotaciones, clasificadas en la categoría de "comercio". Entre los once volúmenes referentes al comercio, en su compilación se encontraba una copia de Britannia Languens, la declaración clásica de la oposición a las plantaciones americanas presentadas al Parlamento de Inglaterra en $1680 .^{5}$ Locke no sólo leyó sobre América y los argumentos referentes a la colonización, también escribió apuntes y ensayos sobre el tema. Además de los argumentos a favor del comercio internacional en su famosa Some Considerations of the Consequences of the Lowering of Interest, existen otros trabajos de la colección Lovelace que incluyen trabajos y apuntes no publicados sobre el comercio. En todos sus escritos sobre economía, Locke defiende la colonización y el comercio como la mejor manera para incrementar el influjo de dinero a Inglaterra. ${ }^{6}$

${ }^{4}$ Para tener una lista de la compilación de obras de Locke ver: John Harrison and Peter Laslett, The Library of John Locke, 1965, Oxford.

${ }^{5}$ La obra de Harrison and Laslett, The Library of John Locke, 1971, Oxford, enumera la lista de libros incluidos en la compilación de Locke según su propia clasificación. Entre los once libros listados por Locke bajo el rubro 'Comercio' se encuentran: S. Bethel, An Account of the French Usurption on the Trade of England, 1679, London; The Ancient Trades Decayed Repaired Again, 1678, London; W. Petyt, Britannia Languens or a Discourse of Trade Shewing the Grounds and Reasons of the Increase and Decay of Land Rents, National Wealth and Strength, 1680, London.

${ }^{6}$ Locke, Some Considerations of the Consequences of the Lowering of Interest, Locke on Money, Patrick Kelly (ed.), 1991, Oxford, p. 222-3. "Locke, Notes on Trade in Sweden, Denmark and New England", 1696, Bodleian Library, M. S. Locke, c. 30, folio 38. "Notes for an Essay on Trade", 1674, Bodleian Library, M. S. Locke, c. 30, folio 18. "Of the American Plantations", Bodleian Library, M. S. Locke, d. 7, p.l. Este documento fue añadido a la colección Lovelace por Peter King el 8 de octubre de 1714. 
Patrick Kelly, editor de los escritos de Locke, comenta: "Locke sostiene que Inglaterra no tiene otra opción más que fomentar su comercio exterior."7

Además de su colección de libros, existe una evidencia considerable sobre la magnitud que la política colonial tuvo en la obra de Locke de 1668 a 1675, cuando fungió como secretario del Lord de los Propietarios de Carolina y del Consejo de comercio y plantaciones. Desde que se tienen registros de Carolina, se puede apreciar que la mayoría de las cartas fueron firmadas por Locke; algunas leyes, incluso las Leyes temporales de 1674, fueron escritas a mano y enviadas por él, así como un sinnúmero de notas que resumían las actividades también fueron escritas por su puño y letra. Además, escribió a los principales funcionarios en las colonias de las Bahamas y Carolina, incluyendo a Joseph West, Peter Colleton y Henry Woodward sobre su propio acuerdo en aquel tiempo. Finalmente, fue responsable, junto con Shaftesbury, de redactar las Constituciones de Carolina. ${ }^{8}$

H. R. Foxbourne describe el papel central que Locke desempeñó en la administración de Carolina:

Su influencia en lo referente al manejo detallado [de la colonia] parece haber sido de lo más extraordinario y el entusiasmo mostrado por él en el esfuerzo para asegurar la propiedad del asentamiento fue sorprendente. En el otoño de 1672, continuó su informal pero arduo oficio como secretario de propietarios. ${ }^{9}$

${ }^{7}$ Patrick Kelly (ed.), Locke on Money, 1991, Oxford, p. 39.

${ }^{8}$ Trabajos de Shaftesbury, Public Record Office 30. Ver también, Collections of the South Carolina Historical Society, V, 1897, Charleston, Calendar of State Papers, Colonial Series: America and West Indies (1661-1668), Noel Sainsbury (ed.), 1880, London.

${ }^{9}$ H. R. Foxbourne, The Life of John Locke, I, 1876, London, p. 244. Aunque Foxbourne señala el año 1672 como el último de trabajo para el Consejo, Locke asistió a reuniones hasta 1675. 
BARBARA ARNEIL

En el Consejo de comercio y plantaciones, donde fue secretario de 1673 a 1675, su trabajo también fue exhaustivo, como lo señala George Breer:

El Consejo de Plantaciones y su extensión tuvieron una vida conjunta de poco más de cuatro años; durante este breve período, mejoraron enormemente todo el sistema de control imperial. Mantuvieron juntas formales con un promedio de dos veces por semana. ${ }^{10}$

Los contactos que Locke realizó a través de Carolina y el Consejo de comercio le brindaron una oportunidad para averiguar más sobre los amerindios. La correspondencia entre Locke y los colonizadores americanos nos ofrece una evidencia de su profundo interés. En una carta fechada el 4 de septiembre de 1676, Joseph West, gobernador de Carolina, le escribe:

Su carta del 10 de junio acaba de llegar...a mis manos, la cual respondí camino a Bermuda y ahora le envío dándole a usted el mejor informe con respecto a los nativos de aquí; espero que sacie tanto sus expectativas como las de otros caballeros. ${ }^{11}$

Otra carta dirigida a Locke y fechada el 12 de noviembre de 1675 por parte del Dr. Henry Woodward, un colono de Carolina que fungió como vínculo entre los colonos y las tribus locales, dice:

He realizado la mejor investigación posible en lo que concierne a la religión y adoración al Dios único, así como a las cos-

${ }^{10}$ George Beer, The Old Colonial System (1660-1754), 1912, New York, I, p. 249.

${ }^{11}$ Carta de Joseph West a Locke, 4 de septiembre de 1676, Correspondence of John Locke, I, Esmond de Beer (ed.), 1976-1982, Oxford, Carta n 318. 
tumbres de nuestros nativos, en especial de los indios de Port Royall con quienes estoy más familiarizado. ${ }^{12}$

\section{La oposición al colonialismo}

La participación de Locke en el desarrollo de una política colonialista ocurrió en el momento en que la opinión de la mayoría en Inglaterra se oponía firmemente a ésta. Sir Josiah Child, a quien Locke responde en su obra Some Considerations of the Consequences of Lowering the Interest, afirma en su afamado New Discourse on Trade, que aquellos que favorecen la colonización del nuevo mundo por parte de Inglaterra sólo son, como Charles lo era, uno entre mil. "Donde hay uno que comparte mi opinión, puede haber mil que opinen lo contrario." ${ }^{13} \mathrm{Del}$ mismo modo, en su obra England Treasure by Forraign Trade, Thomas Mun escribió que era "la primer obra de interés específicamente económico que se sepa que Locke haya leído", 14 en apoyo al comercio exterior y las plantaciones; sin embargo, coincidía con Child en que éste era el punto de vista de una minoría.

Esta postura es tan contraria a la opinión pública que requerirá de varios fundamentos sólidos para probarla antes de que sea aceptada por la multitud, que protesta amargamente cuando ve cómo sale del Reino la más mínima cantidad de dinero. ${ }^{15}$

Estas muestras de oposición no son exageradas por parte de aquellos que defienden la plantación con fines retóricos. El informe del

${ }^{12}$ Carta del Dr. Henry Woodward a John Locke, 12 de noviembre de 1675, Correspondence, $\mathrm{I}$, Carta $\mathrm{n}^{\circ} 305$.

${ }^{13}$ Sir Josiah Child, A New Discourse on Trade (1689), 1804, London, p. 170.

${ }^{14}$ Kelly (ed.), Locke in Money, I, p. 98.

${ }^{15}$ Thomas Mun, England's Treasure by Forraign Trade (1664), 1949, Oxford, p. 14. 
BARBARA ARNEIL

Comisionado de aduanas, Britannia Languens, y los tratados de eminentes figuras públicas como Sir William Coventry, John Evelyn y Roger Coke dan evidencia de que dicha postura se mantenía ampliamente. ${ }^{16}$

La fuerte oposición a las actividades de Inglaterra en América no estaba basada exclusivamente en los aspectos económicos. Durante el siglo XVII surgieron preguntas sobre el derecho de Inglaterra de apropiarse de tierra que ya estaba ocupada por otra gente. Quizás el caso más famoso sea el del Reverendo Roger Williams, ministro de Salem, quien proclamó públicamente que "el Rey no tenía derecho alguno de otorgar tierras, de las cuales se había apropiado la colonia, ya que pertenecían a las tribus Indias". ${ }^{17}$ Williams fue arrestado y llevado a juicio. Aunque más tarde fue desterrado, Williams provocó, gracias a su juicio en la corte, el debate de cómo se debería establecer el derecho a la propiedad. John Winthrop, gobernador de Massachusetts, entre otros, fue forzado a dar una respuesta. El debate realizado a mediados del siglo XVII fue intenso y decisivo, en las colonias generalmente pobladas por religiosos puritanos.

${ }^{16}$ Britannia Languens, o A Discourse of Trade Humbly Offered to the Consideration of this Present Parliament (publicado por vez primera en 1680), reeditado para Richard Baldwin, 1689, London; Sir William Coventry escribió: 'la extensa y continua dirección de la gente joven y prolífica de las plantaciones' fue la causa de la decadencia en Inglaterra, "Essay Concerning the Decay of Rents and their Remedies", citado en Beer, The Old Colonial System, 1660-1754, 1912, New York, I, p. 21-2. John Evelyn, comisionado oficial para el Consejo de comercio y plantaciones de 1672, quien nombró a Locke secretario del Consejo, escribió sobre "el número devastador de nuestros hombres que acuden en masa a las plantaciones americanas día tras día", Navigation and Commerce, 1674, p.11, citado en Beer, The Old Colonial System, I, p. 22, nota 2. Roger Coke, A Discourse of Trade in Two Parts, 1670, London.

${ }^{17}$ Cfr., The Cambridge History of the British Empire, 1929, Cambridge, I, p. 163-4. Merece la pena recalcar que Roger Williams antes de emigrar a América era el capellán de la familia Masham que vivía en High Laver, lugar donde Locke pasó los últimos años de su vida (1691-1704). 
Así Locke, que estaba profundamente comprometido e interesado en el éxito de la colonización de América y al tanto de la fuerte oposición a ésta, en su teoría sobre la propiedad a la larga utilizó varios fundamentos ya empleados por aquellos colonizadores que defendían los derechos de Inglaterra a apropiarse de la tierra americana. Al examinar las premisas y parámetros de razonamiento que fueron desarrollados por Winthrop y otros defensores de los reclamos de Inglaterra contra los de los amerindios, se mostrará de manera específica cómo fueron incorporados dentro del Segundo tratado.

\section{La defensa colonial}

Cuando fueron desafiados por las acciones del Rev. Roger Williams y otros al defender el derecho de Inglaterra a tomar posesión de la tierra de los aborígenes, varios colonizadores importantes escribieron sus propios tratados. Entre los principales se encuentran Virginia's Verger de Samuel Purchas, General Considerations for Planting New England del gobernador de Massachusetts, John Winthrop, Reasons and Considerations Touching the Lawfulness of Removing Out of England into the Parts of America del Rev. Robert Cushman, A Good Speed to Virginia de Robert Gray, The Historie of Travaile into Virginia del primer secretario de Virginia, William Strachey, y A True Report of the Late Discoveries del aventurero principal de Terranova, Sir George Peckham, todos ejemplos de la defensa europea de su derecho en América. ${ }^{18}$ Es a esta tradición y como respuesta a preguntas similares dadas a los defensores de la plantación que John Locke escribió.

${ }^{18}$ Samuel Purchas fue el autor y editor de una colección definitiva de volúmenes de viajes titulada Purchas 's Pilgrims, John Winthorp fue el primer gobernador de Nueva Inglaterra. Robert Cushman fue un importante miembro y ministro laico de Massachusetts. Robert Gray fue el primero en escribir un folleto que vendia Virginia a potenciales colonizadores en Inglaterra. William Strachey fue el primer secretario de la colonia de Virginia y Sir George 
Todos los escritores colonialistas comienzan con una pregunta $u$ objeción formulada por aquellos que ponen en tela de juicio el derecho de Inglaterra de asentarse en América. Purchas pregunta, "entonces, ¿qué derecho tiene Inglaterra en desafiar a Virginia?"; Winthrop inquiere, "¿qué justificación tenemos nosotros, los hijos de Adán, de tomar la tierra que es y ha sido posesión de otros?"; Gray formula la pregunta directamente: "La primer objeción es, ¿con qué derecho o justificación podemos nosotros entrar en la tierra de estos salvajes, quitarles su herencia legítima y asentarnos ahí?" Finalmente, Cushman declara: "Algunos dirán: ¿Qué derecho tengo yo de vivir en el país de los salvajes?"19

Era una pregunta que predominaba en el debate de los asuntos colonialistas durante el siglo XVII. William Strachey, Primer Secretario de la Colonia de Virginia, escribe que no hay otro asunto que haya causado tanta consternación.

[Del] reclamo que hemos hecho de esta parte de América... he observado y clamado (pensé yo) y todavía lo pienso, denunciarla y llamarla una empresa ilegal y antinacional... ¿Por qué?

Peckham fue jefe aventurero en Terranova. Las obras que se utilizaron fueron las siguientes: Samuel Purchas, "Virginia's Verger" en Hakluytus Posthumous or Purchas's Pilgrims Containing a History of the World in Sea Voyages and Lande Travells by Englishmen and Others, XIX, 1906, Glasgow; John Winthrop, General Considerations for Planting New England (1629) en Alex Young, Chronicles of the First Planters of the Colony of Massachusetts Bay (1623-1636), 1846, Boston; Robert Gray, A Good Speed to Virginia, 1937, New York; Robert Cushman, "Reasons and considerations touching the lawfulness of removing out of England into the parts of America", en Alexander Young, Chronicles of the Pilgrim Fathers of the Colony of Plymouth (1602-1625), 1841, Boston; William Strachey, The Historie of Travaile into Virginia (1612), 1849, London; Sir George Peckham, "A True Report of the Late Discoveries" en Hakluyt's Voyages, Vill, 1904, Glasgow.

${ }^{19}$ Samuel Purchas, "Virginia's Verger", p. 222; John Winthrop, General Considerations, p. 275; Robert Gray, Good Speed, C 3; Robert Cushman, "Reasons", p. 242. 
Porque es una injuria contra la naturaleza; por lo tanto, (según ellos) esto no puede ser otra cosa sino un trabajo de pura impiedad y algo que no agrada a los ojos de Dios. ${ }^{20}$

Quizás la suposición más importante que se haya hecho en estos tratados es que América podría ser considerada como un vacuum domicilium o tierra vacante abierta a todos para su posesión. Samuel Purchas califica a los ingleses como gente que "busca albergue en lugares vacantes"; George Strachey se refiere a "sus tierras baldías vastas, deshabitadas por ellos mismos" mientras Cushman describe a América simplemente como "vacía". ${ }^{21}$ La tierra vacante tiene una connotación peyorativa en estos escritos, ya que son los habitantes quienes la rechazan activamente al no poseerla apropiadamente ni cultivarla adecuadamente. Por ende, si no existe una señal de propiedad privada la tierra puede ser identificada como vacante. Purchas concluye que los ingleses pueden poseer la tierra vacante, "especialmente donde la gente es salvaje y no demuestre ninguna señal de asentamiento y posesión". Robert Gray, de Virginia, escribe que "estos salvajes no tienen una propiedad en particular en ninguna parte o porción de terreno en ese país, sino sólo una residencia general ahí". John Winthrop escribe que "lo que es común a todos, no pertenece a nadie. Estos salvajes rigen en varias tierras sin ningún título o propiedad". 22

Locke, en su capítulo sobre la propiedad, se refiere en repetidas ocasiones a la tierra que está vacante o deshabitada; en este contexto, América es el ejemplo dado más frecuentemente. Locke define de manera explícita el término deshabitada en el párrafo 42 al impartir de manera simultánea una connotación peyorativa a la tierra que yace allí, en

${ }^{20}$ William Strachey, The Historie of Travaile, op. cit., p. 1-3.

${ }^{21}$ Purchas, "Virginia's Verger", op. cit., p. 222; Strachey, The Historie of Travaile, op. cit., p. 19; Cushman, "Reasons", op. cit., p. 243.

${ }^{22}$ Purchas, "Virgina's Verger", op. cit., p. 222; Gray, Good Speed, C 3; Winthrop, General Considerations, op. cit., p. 275-6. 
BARBARA ARNEIL

común, e invoca una correlación directa e inversa a las formas de cultivo europeas.

La tierra que es abandonada a las manos de la naturaleza, que no tiene uso alguno para el pastizal, cultivo o siembra es, en efecto, deshabitada; debemos encontrar su beneficio, lo cual es poco más que nada. ${ }^{23}$

En el párrafo 36 Locke se refiere a "los lugares tierra adentro de América vacantes", y en el 37 les llama "el lote baldío sin cultivar de América". En ambos casos el término baldío, considerado como antónimo de cercado y cultivado, se localiza en América. ${ }^{24}$ Como los colonialistas, Locke piensa que la deshabitada también puede ser definida como tierra que no se ha trabajado de manera apropiada, llamándola "descuidada y consecuentemente, una tierra desperdiciada". ${ }^{25} \mathrm{El}$ uso del término descuidada en los escritos coloniales es importante, ya que en caso de que se haya utilizado por otra gente, puede juzgarse que ésta ha renunciado a cualquier derecho con su simple descuido y así poner la tierra a disposición de otros. Por lo tanto, Locke habla del individuo quien "por su industria sobre la tierra descuidada y por consiguiente deshabitada, [incrementa] la reserva de maíz". ${ }^{26}$

La libre ocupación de América estaba frecuentemente vinculada con las descripciones de una población desbordante en Inglaterra y el deseo de trasladarse de la gente. El tema de una América vacía y una Inglaterra poblada generalmente está impregnado de una importancia teológica. Los autores comentan que la tierra aborigen tiene un paralelismo con las tierras bíblicas al comparar a los indios con las tribus nómadas de las primeras colonizaciones de Oriente Medio. Así, poblar la tierra tiene proporciones míticas que van de acuerdo con los éxodos

${ }^{23}$ Locke, Two Treatises, op. cit., II, párrafo 42.

${ }^{24}$ Ibid., párrafos 36 y 37.

${ }^{25} \mathrm{Ibid}$, párrafo 36 .

${ }^{26}$ Ibid. 
descritos en los primeros libros del Antiguo Testamento. Roy Harvey Pearce escribe:

Demostrar la ocupación de la tierra ha sido fácil, aun para los puritanos, precursores peregrinos... los indios eran salvajes y por ende, necesitaban la conversión... las tierras de los indios estaban deshabitadas, las tierras Inglesas pobladas; por lo tanto, los ingleses estaban listos para partir a las tierras de los indios y ocuparlas. ${ }^{27}$

Cushman utiliza esta aproximación de vacío y lleno en su tratado sobre el derecho de Inglaterra sobre el "país salvaje".

Deberíamos...procurar y utilizar los medios para convertir a los salvajes; y los medios no pueden ser utilizados a menos que nosotros vayamos hacia ellos o que ellos vengan hacia nosotros. Ellos no pueden venir hacia nosotros, nuestra tierra ya está habitada; nosotros podemos ir hacia ellos, su tierra está vacía. ${ }^{28}$

En su folleto de Virginia, Robert Gray describe los problemas de la sobrepoblación en su país:

Esto nos debe enseñar a los habitantes de este reino y país, prudencia y providencia, pues el Señor nos ha bendecido, $y$ que nos hemos desarrollado para ser un gran pueblo a fin de que un lote no sea suficiente para nosotros: Nuestras multitudes, como demasiada sangre en el cuerpo, infectan nuestro país con peste y pobreza. $^{29}$

${ }^{27}$ Roy Harvey Pearce, "The 'Ruines of Mankind': The Indian and the Puritan Mind", Early American History: Indians and Europeans, Selected Articles on Indian-White Relations in Colonial North America, 1988, New York, Peter Hoffer (ed.), p. 32.

${ }^{28}$ Cushman, "Reasons", op. cit., p. 243.

${ }^{29}$ Gray, Good Speed, op. cit., B 3. 
John White, autor de The Planter's Plea, describe a Inglaterra en términos similares, y señala a América como el país para absorber el exceso. "La tierra tiene la capacidad de ofrecer suficiente terreno vacío para recibir más gente de lo que este estado [Inglaterra] puede hacerlo." 30

Locke hace una distinción similar entre la tierra que está poblada en Inglaterra y la desocupación de tierra en el estado original. Concluye que las reglas de apropiación son diferentes en cada una.

Es verdad, que la tierra, que es bien común en Inglaterra o en cualquier otro país, donde haya mucha gente [el énfasis es mío] bajo un gobierno, cuya gente tiene dinero y comercio, nadie puede ocupar o poseer parte de esta tierra sin el consentimiento de sus conciudadanos. ${ }^{31}$

Continúa diciendo que en el estado de naturaleza que es América, "era muy distinto. El hombre de ley estaba por debajo, estaba más bien llamado a la posesión. Dios mandaba y Su voluntad orilló a este hombre al trabajo". 32

44 Dado que América estaba deshabitada, abierta a la posesión y podía absorber un desbordamiento de población inglesa, muchos de estos escritores recurrieron a la Biblia para ofrecer la justificación teológica específica para dicho desplazamiento. El ejemplo utilizado con mayor frecuencia es el de Abraham y Lot, quienes buscaban nuevas tierras y cuyos rebaños habían crecido en un tamaño considerable: "las tierras ya no podían saciar su hambre". Lot va a Jordania y Abraham se dirige a Canán donde Dios [le] dice: "Levántate, recorre el país a lo largo y a lo ancho, porque a ti te lo he de dar." 33 Probablemente, Samuel Purchas

${ }^{30}$ John White, The Planter's Plea, citado en Chester Eisinger, "The Puritans, Justification for Taking the Land", Essex Institute Historical Collections, 1948, LXXXIV, p. 138.

${ }^{31}$ Locke, Two Treatises, op. cit., II, párrafo 35.

32 Ibid.

${ }^{33}$ Génesis 13. 
sea el primero en utilizar este pasaje de la Biblia en particular a fin de justificar la apropiación de la tierra por parte de los ingleses en América:

La misma razón dio la libertad a otros hombres que desean un lugar adecuado para asentarse... especialmente donde la gente es salvaje y no posee ninguna tierra en ninguna parte. Por ende, los santos patriarcas [es decir, Abraham, Lot y Jacob] acamparon en esas tierras y pastizales, cuando aquellas regiones todavía estaban despobladas: y así el mundo entero se asentó y pobló con colonias anteriores y posteriores y, por ende, Virginia ofreció espacio suficiente para su población. ${ }^{34}$

Winthrop también hace una referencia específica a este pasaje bíblico:

¿Y por qué no los cristianos tienen la libertad de ir y habitar entre ellos en sus tierras baldías y bosques... tan legalmente como Abraham lo hizo entre los sodomitas? (Génesis xiii). ${ }^{35}$

Otro colonizador, Solomon Stoddard, emplea la misma referencia:

Había una parte de la tierra que no fue adquirida, ni había la necesidad de hacerlo; era un vacuum domicilium... Por ser la primera promesa de Dios, la humanidad tenía que dominar la tierra. Cuando Abraham llegó a la tierra de Canán, utilizó la tierra vacante como él quiso. ${ }^{36}$

Por último, Cushman utiliza también el mismo pasaje del Génesis para justificar el derecho de Inglaterra sobre América.

${ }^{34}$ Purchas, "Virginia's Verger", op. cit., p. 222.

${ }^{35}$ Winthrop, General Considerations, op. cit., p. 276. Mi énfasis en esta cita y las otras continuarán con el tema.

${ }^{36}$ Solomon Stoddard, "An Answer to Some Cases of Conscience", The Puritans, 1938, New York, P. Miller y T. Johnson (eds.), p. 457. 
BARBARA ARNEIL

Como los antiguos patriarcas salieron de lugares más pequeños en busca de lugares más espaciosos donde la tierra estaba sin trabajar y baldía, y nadie la utilizaba, aunque ya habitada; como dice el Génesis... así que ahora es legal tomar la tierra que nadie ha utilizado y hacer uso de ella. ${ }^{37}$

El empleo del capítulo 13 del libro del Génesis es importante, ya que en su capítulo sobre la propiedad Locke se refiere al mismo pasaje para dar un ejemplo de la tierra baldía que puede ser legítimamente apropiada en el estado de naturaleza cuando, como en el caso de Abraham, alguien puede habitar en otra tierra.

Pues hemos visto, que en aquella parte del mundo que en un principio estuvo habitada, y por ende, es mejor que esté habitada, aun desde tiempos remotos como los tiempos de Abraham... cuando no había espacio suficiente en el mismo lugar, ya que sus manadas pacían juntas, ellos, por común acuerdo, como Abraham y Lot lo hicieron, se separaron e incrementaron su pastizal donde mejor les pareció (Gen. xiii, 5). ${ }^{38}$

El principio es el mismo tanto para Locke como para los otros escritores. No sólo es legal sino agradable a los ojos de Dios que la gente que ha sido trabajadora y haya utilizado sus propias tierras y recursos deba desplazarse a otro lugar cuyos habitantes no hagan uso de la tierra. La idea que Dios le dio a Abraham ese terreno "largo y ancho" de la tierra nueva no se pierde en aquellos escritores colonialistas o en el Rey, quien les ofrece las patentes. Para los ingleses, tanto el derecho natural del reclamo de las tierras como la justificación teológica para tal apropiación se enraizaban en el trabajo y en la industria.

El trabajo de la tierra consiste principalmente en cercarla y cultivarla, por lo tanto, para estos escritores el reclamo de la propiedad sobre un pedazo de tierra incluía dos etapas: el primero, cercarla; el segun-

${ }^{37}$ Cushman, "Reasons", op. cit., p. 243-4.

${ }^{38}$ Locke, Two Treatises, op. cit., II, parráfo 38. 
do, cultivarla. Son estos dos elementos los que distinguen el uso de la tierra de los ingleses del aborigen. En lo referente al primer elemento, Winthrop añade a su descripción de los amerindios que no poseen tierra alguna, citada anteriormente, la siguiente explicación, "puesto que no cercan ningún terreno ni tampoco tienen ganado para cercarlo", y continúa diciendo que los ingleses "se apropiaron de algunas parcelas de tierra al cercarlas". ${ }^{39}$ Esta necesidad de cercado se sentía tan profundamente que los gobiernos coloniales con frecuencia forzaban a los amerindios a cercar sus predios con el objeto de comprobar su propiedad. Osgoode escribe, "Plymouth y Massachusetts... dieron la orden que los maizales de los indios deberían estar cercados... Connecticut buscó el mismo objetivo a través de una orden general". ${ }^{40}$

El cercado fue utilizado por Locke en varias ocasiones en su capítulo sobre la propiedad. Su definición inicial de la propiedad privada de la tierra declara que: "Él, como si por su trabajo le perteneciera, la cercará y separará de los demás." 41 Locke vuelve a introducir la idea de cercado en cada aspecto de su argumento. En el párrafo 33, el cercado es comentado en relación al daño de los derechos de otros, en el párrafo 38 en relación con el desperdicio, y en el 48 , en el contexto de la utilización del dinero. ${ }^{42}$ La idea de cercado también se centraba en los planes de los Lores propietarios para la colonización de Carolina, que dependía de la supervisión y trazado de los límites a fin de dar su porción de tierra a cada colonizador. ${ }^{43}$

${ }^{39}$ Winthrop, General Considerations, op. cit., p. 276.

${ }^{40}$ Herbert Osgoode, The American Colonies in the 17th Century, I: The Charterd Colonies: Beginnings of Self-Government, 1904, New York, p. 532. ${ }^{41}$ Locke, Two Treatises, op. cit., II, párrafo 32.

${ }^{42}$ Ibid., párrafos 33, 38 y 48.

${ }^{43}$ Así, las instrucciones de los lores Propietarios a Andrew Percibal en mayo de 1674 eran: "Usted no le otorgará la tierra a nadie que venga a colonizar bajo su régimen, sino bajo la condición de que se asienten en comunidades y se apropien de la tierra de acuerdo con las leyes enviadas a usted." Carta de Shaftesbury al Consejo en Ashley River, 11 de junio de 1675, Saftesbury Papers, Public Records Office, Fajo 48, n 55, p. 156. 
El segundo elemento importante en lo referente al reclamo de la tierra es la aplicación de la industria, especialmente del cultivo agrario. La descripción de Cushman de la tierra aborigen dice:

El país todavía está virgen; la tierra sin cultivar; las ciudades sin construir; el ganado sin asentar. Estamos rodeados de gente inútil y floja, los nativos de este país, no pueden... ayudarse a sí mismos, mucho menos a nosotros. ${ }^{44}$

La Corte General de Massachusetts dejó clara la importancia del cultivo al considerar el reclamo de los Amerindios sobre el derecho natural de la propiedad; en su juicio:

probó manifiestamente que los indios que sólo tenían un derecho natural a demasiada tierra como la tenían o podrían cultivarla, luego entonces el resto del país estaba abierto a cualquiera que pudiera cultivarla. ${ }^{45}$

Para Locke, el cultivo de la tierra yace en el corazón de los derechos de propiedad sobre la tierra. Inmediatamente después de formular la pregunta de la tierra en el capítulo cinco, asevera que el principio que gobiema la propiedad privada es esta forma específica de trabajo:

Mientras más tierra sea trabajada, cultivada y mejorada por el hombre y pueda sacar provecho de ella con sus frutos, más será de su propiedad. Él, como si por su esfuerzo le perteneciera, la cercará y separará de los demás. ${ }^{46}$

${ }^{44}$ Robert Cushman, "Discourse: The State of the colony and the need of public spirit in Colonists", Chronicles of the Pilgrim Fathers, 1841, Boston, Alexander Young (ed.), p. 265.

${ }^{45}$ Eisinger, "The Puritans, Justification for Taking the Land", op. cit., p. 136.

${ }^{46}$ Locke, Two Treatises, op. cit., II, párrafo 32. 
A lo largo del capítulo de Locke sobre la propiedad existen referencias en lo que toca al cultivo agrario de la tierra. En el párrafo 35, habla sobre el "cultivo" de la tierra; en el 36, sobre el "arado, la siembra y la cosecha"; en el 37, sobre el "labrado o trabajo de la tierra", y en 42, sobre el "pastizal, labrado y siembra".

Para muchos escritores - inclusive para Locke- es evidente que Dios heredó América a quienes la cultivaran. Piensa John White:

Él... nunca ofrece un regalo que no se disfrute: la manera en que la humanidad se beneficie de la tierra, a través de su cultivo y habitación aún no puede ser imaginada. ${ }^{47}$

Winthrop escribe:

Toda la tierra está en el jardín del Señor, y se les ha dado a los hijos de Adán para que sea cultivada y labrada por ellos. Entonces, ¿por qué permanecemos aquí hambrientos de espacios y habitación... y mientras tanto países enteros sufren, siendo esta tierra destinada al uso del hombre, a que siga baldía sin sembrarse ${ }^{48}$

En el párrafo 34 sobre la propiedad, Locke recalca el mismo punto:

Dios dio el mundo a la humanidad; pero no es de suponerse que su intención era que este mundo siempre permaneciera sin cultivarse y en común para todos. Él se lo dio a los trabajadores y racionales (y el trabajo habría de ser su titulo). ${ }^{49}$

En el párrafo 37 Locke aclara quiénes son los trabajadores cuando compara el valor de 1000 acres de "tierra baldía sin cultivar en América" con " 10 acres de tierra fértil similar... en Devonshire", que ha sido

${ }^{47}$ White, The Planters' Plea, op. cit., p. 138.

${ }^{48}$ Winthrop, General Considerations, op. cit., p. 272.

${ }^{49}$ Locke, Two Treatises, op. cit., II, párrafo 34. 
"bien cultivada" por granjeros ingleses. De nuevo, en el párrafo 41, Locke se refiere a "varias naciones de los americanos", quienes, "por querer cultivar [la tierra] por medio del trabajo, no tienen la centésima parte de las ventajas que los ingleses disfrutan".

Para Locke, como para los otros colonizadores, los amerindios, no sólo adolecen de industria sino de la aplicación de la razón y el desarrollo de las artes así como de la ciencia. Cushman describe sucintamente las carencias de los amerindios: "No son trabajadores, tampoco tienen arte, ciencia, aptitudes o facultades para utilizar la tierra o frutos que ésta les brinde." 50 También para Locke, es a los "trabajadores y racionales" a quienes Dios dio la tierra. Como los escritores colonialistas, él cree que los amerindios han fracasado en lo referente al desarrollo de su raciocinio. En Essay Concerning Human Understanding, escribe:

[Existen] naciones enteras... entre las cuales... la naturaleza sin cultivar se ha dejado a su merced, sin la ayuda de cartas, disciplina y los avances de las ciencias y las artes. ${ }^{51}$

El desarrollo de las artes y las ciencias, según Locke, es un mandato que proviene de la Biblia y tiene un vínculo muy cercano al primer dominio otorgado por Dios a todos los hombres sobre la tierra. En el Primer tratado, Locke escribe:

Esta primera y grandiosa bendición de Dios todopoderoso, Sed fructíferos, multiplicad y poblad la tierra..., incluye también el desarrollo de las artes y las ciencias y los provechos de la vida. ${ }^{52}$

${ }^{50}$ Cushman, "Reasons", op. cit., p. 243.

${ }^{51}$ John Locke, Essay Concerning Human Understanding, 1975, Oxford, Book I, cap. IV, sec. 8 .

${ }^{52}$ Locke, Two Treatises, op. cit., I, párrafo 33. 
Comenta que los amerindios tienen el potencial de ser trabajadores y racionales, pero sólo si están dispuestos a renunciar a ellos mismos durante el proceso. En su Ensayo, concluye:

Si el Rey de Virginia Apochancana hubiera sido educado en Inglaterra, [habría sido] tan buen matemático como cualquiera. La diferencia entre él y un hombre inglés educado yace en: Que el ejercicio de sus facultades estaban delimitadas en sus formas, modos y conocimiento de su propio país... nunca emplearon las partes, facultades y poderes para el trabajo; más bien se conformaron con modas e instrumentos de su país, así como los descubrieron, sin ver más allá. ${ }^{53}$

Los ingleses son trabajadores y racionales y, por ende, gracias a su trabajo, son los propietarios legítimos de la tierra americana. Los amerindios se pueden volver trabajadores y racionales, según Locke, sólo si están dispuestos a renunciar a sus propias costumbres en favor de "la razón".

Al comparar la capacidad de trabajo de los ingleses y los amerindios, el valor del trabajo es descrito tanto por Locke como por los primeros defensores de las plantaciones inglesas en términos de proporciones. Por ejemplo, la tierra puede rendir diez veces o cien veces más según la adecuada aplicación del trabajo. Frecuentemente estas proporciones se asemejan a una comparación entre la fertilidad del suelo americano y la escasez de dinero de los ingleses, y la necesaria conclusión de esta industria es lo que marca la diferencia. Purchas lo plasma exactamente en estos términos:

No son más de 5,000 hombres capaces de trabajar con sus brazos, los cuales utilizados de manera civilizada bien podrían dar de comer a 1,500,000 y muchos, muchos más; en cambio,

${ }^{53}$ Locke, An Essay Concerning Human Understanding, op. cit., Book I, cap. IV, sec. 12. 
BARBARA ARNEIL

en nuestro país [Inglaterra] aparentemente se da el caso sin tener una herencia natural tan rica. ${ }^{54}$

Las proporciones de Winthrop son decididamente más bajas en términos de trabajo, pero reflejan una comparación similar entre la aplicación de la industria en Inglaterra y América, donde los rendimientos serían 100 veces mejores en lo referente a la extensión de tierra fértil.

Muchos hombres, que se pasan mucho tiempo en el trabajo y les cuesta recuperar o a veces mantener un acre o dos de terrenos [en Inglaterra], buscan muchos cientos de acres, para su bienestar o progreso, en otro lugar [es decir, Virginia]. ${ }^{55}$

Stratchey, al igual que Purchas, plasma la proporción de 1 a 1,000.

En sus terrenos deshabitados baldíos y vastos, de los que no sabrían aprovechar uno de 1,000 acres. $^{56}$

Locke, al comparar el valor de un acre de tierra cultivada en Inglaterra con un acre en América, utiliza proporciones similares.

Las provisiones que sirven para dar apoyo a la vida humana, producidas por un acre cultivado de terreno cercado, equivalen... a diez veces aquellos que dan fruto en un acre de tierra de una riqueza similar, que yace baldía y que pertenece a todos. ${ }^{57}$

El elemento final en todas estas justificaciones en lo referente a los reclamos ingleses en América es que no causarán daño alguno a los amerindios. Más bien, éstos sacarán mayor provecho del conocimiento, aptitudes y tecnología de los ingleses. En primer lugar, no puede haber

${ }^{54}$ Purchas, "Virginia's Verger", op. cit., p. 222.

${ }^{55}$ Winthrop, General Considerations, op. cit., p. 272.

${ }^{56}$ Strachey, The Historie of Travaile, op. cit., p. 19.

${ }^{57}$ Locke, Two Treatises, op. cit., II, párrafo 37. 
daño alguno porque hay más que suficiente en lo que respecta al uso de la tierra tanto para los ingleses como para los amerindios. Purchas escribe:

Y si un país puede habitarse en algunos lugares, mientras que otros permanecen deshabitados, la misma razón dio la libertad a otros hombres que quisieron un lugar adecuado para que se asentaran, donde ( $\sin$ hacer daño a otros) puedan subsistir por sí mismos. ${ }^{58}$

De igual forma, Winthrop da como una de las razones del por qué los ingleses no pueden hacer daño alguno a los amerindios: "Hay más de lo necesario para ellos y para nosotros". 59 Locke toca el mismo punto:

Tampoco tuvo esta apropiación de cualquier pedazo de tierra al cultivarla ningún perjuicio a otros hombres, ya que todavía había suficiente tierra buena y se podía utilizar más de la necesaria... Nadie puede pensar en hacerle daño a otro hombre al beber el agua del mismo río, pues esas aguas son suficientes para saciar la sed de todos. ${ }^{60}$

Muchos de los defensores del derecho de Inglaterra sobre la apropiación afirman que el conocimiento y la tecnología traídos de Europa, lejos de provocarles algún daño sólo beneficiaría a los amerindios. Strachey escribe:

Tampoco es en perjuicio alguno de quienes no tomaremos por la fuerza su sustento ni sus labores... sino preparar y fincar nuevas tierras, y así abrirles también un nueva forma de economía y manutención. ${ }^{61}$

${ }^{58}$ Purchas, "Virginia's Verger", op. cit., p. 222.

${ }^{59}$ Winthrop, General Considerations, op. cit., p. 277.

${ }^{60}$ Locke, Two Treatises, op. cit., II, párrafo 33.

${ }^{61}$ Strachey, "Virginia", op. cit., p. 19. 
BARBARA ARNEIL

Este argumento llega hasta tal punto, que unos cuantos observadores concluían que, de hecho, los Amerindios darían la bienvenida a los ingleses en sus tierras con el objeto de beneficiarse de la cultura superior, la religión y el conocimiento agrícola. Francis Higginson, escribe en su obra New England's Plantations:

[Los indios] profesan su beneplácito sobre nuestra llegada y cultivos aquí... porque hay abundancia de tierra la cual no poseen para su utilización. ${ }^{62}$

Winthrop coincide con este punto de vista: "Llegaremos con la buena licencia de los nativos." ${ }^{63}$ Locke hace un comentario semejante: "Los mismos habitantes [admirarán] a ustedes, quienes, por su industria sobre... la tierra baldía, han incrementado la producción de maíz, que ellos querían." ${ }^{64}$ Locke concluye motivando a sus lectores ingleses a que cultiven las tierras baldías de América sin temor a infligir daño al nativo:

Que plante en lugares baldíos tierra adentro en América; veremos que las posesiones de las que él se pueda hacer... no les darán motivo alguno de queja. ${ }^{65}$

\section{Comercio vs. conquista}

Locke lleva su defensa de los derechos de los colonizadores ingleses más allá de la de Winthrop y otros escritores colonialistas en lo referente al dinero y la conquista, punto central en los escritos de Locke

${ }^{62}$ Francis Higginson, New England's Plantation en Chronicles of the First Planters, p. 257.

${ }^{63}$ Winthrop, General Considerations, op. cit., p. 277.

${ }^{64}$ Locke, Two Treatises, op. cit., II, párrafo 36.

${ }^{65}$ Ibid. 
sobre la economía en las colonias, dando prioridad al primero, como se refleja en su obra Some Considerations:

Existen sólo dos formas de enriquecerse: la conquista o el comercio... Nadie es lo suficientemente vano para tener en mente el derrochar las riquezas del mundo con nuestras espadas y echar a perder a las naciones derrotadas. Por lo tanto, el comercio es la única alternativa para nosotros... ya que éste pone en ventaja nuestra situación así como a la industria y la inclinación de nuestro pueblo... y naturalmente va de acuerdo con nosotros. ${ }^{66}$

Cuando en el capítulo 5 introduce la noción de dinero es, aparentemente, para vencer la condición de desperdicio, si bien el trueque de bienes no perecederos hubiera servido para ese propósito. El verdadero propósito del dinero - "pequeña pieza de metal amarillo", es decir, de oro- para Locke era conducir el comercio en abundancia con el resto del mundo. Por consecuencia, cualquier acre de tierra disponible podría ser apropiado y cultivado en América sólo por aquellos que tuvieran oro y plata, en consecuencia, los amerindios eran incapaces de llevar a cabo esa tarea. Locke escribe: "Los habitantes que no se hayan unido con el resto de la humanidad, en el sentido del uso del dinero en común, han dejado 'grandes porciones de tierra [que yace] baldia'. "Continúa diciendo que con la carencia de acceso al mercado mundial para vender sus productos, los amerindios nunca podrían apropiarse de estas tierras más que para su indispensable subsistencia.

¿Cómo es que un hombre valore diez mil o cien mil acres de tierra excelente... de las parcelas cercadas tierra adentro de América, si no tiene esperanza alguna de vender el fruto en otras partes del mundo para obtener dinero por la venta de ese producto? El cercar la tierra no valdría la pena y lo veríamos de-

${ }^{66}$ Locke, Some Considerations, op cit., p. 222-3. 


\section{BARBARA ARNEIL}

volverle a la naturaleza salvaje común esas parcelas que sólo abastecerían las mínimas necesidades de supervivencia para su familia. ${ }^{67}$

Es el potencial de intercambio de riquezas de la tierra a través del comercio con moneda sólida con otros países lo que motiva y justifica la apropiación masiva de la tierra a través de los intereses colonialistas ingleses, escribe Locke en unos apuntes de un ensayo inédito sobre comercio: "El fin principal del comercio son las riquezas y el poder... las riquezas consisten en una gama de bienes movibles que brinden un precio al extranjero... especialmente mucha plata y oro." 68

Así, el trabajo otorga al amerindio la propiedad, pero sólo en los productos agrícolas y en pequeñas parcelas de tierra, mientras que el uso del dinero otorga al inglés la propiedad en todo lo demás. Locke declara enfáticamente que son éstos, quienes tienen dinero, los poseedores del derecho a posesiones mayores: "La invención del dinero... introdujo (a través de acuerdos) posesiones más grandes y un derecho a ellas" [el énfasis es mío]. Posteriormente, Locke afirma que fue el acuerdo en lo referente a la utilización "del oro y la plata" lo que pone en "evidencia" "que los hombres hayan acordado repartir la posesión de la tierra de una forma desproporcionada y desigual", o sea, todo el mundo. En lo que toca a los criterios de la industria y la racionalidad, Locke no excluye de manera explícita a los amerindios de dicho comercio internacional, sin embargo, piensa que éstos podrían apropiarse de tanta tierra como los ingleses sólo cuando lleguen a un acuerdo en la utilización del oro y la plata como dinero.

Mientras que el dinero era un medio aceptable por el cual los colonizadores podían limitar la apropiación de la tierra a los aborígenes y desarrollar pacíficamente el potencial del suelo americano, la conquista no lo fue. Para Locke y los defensores del colonialismo inglés, la

${ }^{67}$ Locke, Two Treatises, op cit.,párrafos, 45, 48.

68 "Notes for an Essay on Trade", 1674, Bodleian Library, M. S. Locke c. 30 , folio 18. 
guerra era un método español de apropiación, justificada a través de la doctrina católica de una "guerra justa". Más que por la fuerza, los ingleses, habrían buscado la apropiación de la tierra por medios pacíficos, es decir a través de actividades agrarias descritas anteriormente o por medio de la compra de éstas a los amerindios. La teoría de la conquista de Locke en el capítulo 16 del Segundo tratado refleja su punto de vista categórico en lo que respecta a los métodos coloniales de Inglaterra, con una postura que él mismo llama "doctrina extraña", por la que sostiene que la victoria sobre cualquier otro pueblo no implica un derecho sobre sus posesiones. En otras palabras, la tierra no puede adquirirse por la fuerza.

Un conquistador obtiene... un poder absoluto sobre las vidas de aquellos quienes al ponerse en un estado de guerra, las pierden; pero él no tiene ningún derecho ni título sobre esas posesiones. De esto no me cabe la menor duda, aunque a primera vista esto parecerá una doctrina extraña... El derecho de conquista se extiende sólo a las vidas de aquellos que se unieron a la guerra, no a sus bienes. ${ }^{69}$

Locke reconoce tanto en su experiencia personal como en su obra Two Treatises que la colonización pacífica es más una idea que una realidad, existente más en los propietarios de Inglaterra que en los colonizadores del nuevo mundo. En una carta escrita por Locke de puño y letra al gobernador de Carolina el 3 de mayo de 1671, hace mención a que los propietarios amonestaron a los colonizadores por no emplear métodos pacificos de cultivo y comercio y haber utilizado la violencia para apropiarse de las tierra americanas.

Tampoco pensamos que es ventajoso para nuestro pueblo vivir de la rapiña y el pillaje, actividades que no permitimos ni permitiremos. Plantación y comercio es tanto nuestro proyecto

${ }^{69}$ Locke, Two Treatises, op cit., II, párrafos 180, 182. 
BARBARA ARNEIL

como el interés de ustedes, y si siguen nuestras instrucciones les abriremos la brecha para que obtengan todas las riquezas de los españoles en aquel país. ${ }^{70}$

En el capítulo sobre la conquista en el Segundo tratado, Locke reconoce, a través de su experiencia colonialista, que la fuerza o la viólencia son las justificaciones generalmente más aceptadas para poseer tierras nuevas: "No hay nada más familiar cuando se habla del dominio de países que digamos... la conquista..., pues brinda un derecho de posesión." No obstante, en sus escritos sobre economía así como en el capítulo 16 del Segundo tratado, espera ofrecer un nuevo y aparentemente "extraño" modelo de colonización que se ajuste mejor a las disposiciones de los ingleses. Locke concluye en Some Considerations: "Asegurar nuestra navegación y comercio [es] más el interés de este reino que las guerras o la conquista."71

Merece la pena recalcar que John Locke continúa con el debate en Two Treatises, en donde explica que la excepción singular sobre los conquistadores que obtenían el derecho sobre la tierra de otros correspondía cuando la tierra permanecía baldía: "Cuando hay más tierra de la que los habitantes poseen, y nos hacen partícipes de ella, cualquiera puede tener la libertad de utilizar esa tierra baldia." "72 Así, son más bien el trabajo pacífico en la tierra baldía y el comercio, y no la conquista, los que brindan tanto un título justo en el nuevo mundo como un método superior de colonización.

${ }^{70}$ Carta de Lord Ashley (después Conde de Shaftesbury) a William Saile el 13 de mayo de 1671, escrita con puño y letra de Locke, Shaftesbury's Papers, Public Records Office, Bundle 48, $n^{\circ}$ 55, p. 91. Como se señala en este texto, Lord Ashley fue mecenas de Locke (n.r.).

${ }^{71}$ Locke, Some Considerations, op. cit., párrafo 232.

${ }^{72}$ Locke, Two Treatises, op. cit., Il, párrafo 184. 
EL COLONIALISMO Y LOCKE

\section{Conclusión}

De esta manera, el debate sobre el derecho de Inglaterra a ocupar la tierra de otro pueblo desempeña un papel importante en la obra de Locke titulada $T$ wo Treatises, en particular en su capítulo sobre la propiedad. Al igual que los defensores de las plantaciones inglesas, Locke comienza con la premisa de que la tierra en América es principalmente "baldía". De acuerdo con estos escritores, es voluntad de Dios que esta tierra no permanezca sin cultivar y sea disponible al bien común. Al igual que Winthrop, Strachey y Purchas, Locke concluye que es a través del cercado y el cultivo de predios como los colonizadores ingleses cumplirán con los deseos de Dios en el nuevo Canán de América, como Abraham y Lot lo habían hecho según el libro del Génesis. Se pone en tela de juicio que dicho cultivo de tierras no haga daño alguno a los amerindios, sino que les traerá beneficios por medio del conocimiento compartido y mejores cosechas.

Por último, más que a través de la conquista violenta de los pueblos aborígenes locales, el asentamiento inglés debe estar basado en el cultivo pacífico de la tierra baldía. En el contexto del debate candente y las denuncias puritanas sobre la apropiación de la tierra aborigen de Inglaterra como una "obra de llana impiedad y nada agradable a los ojos de Dios", los defensores de la colonización, incluyendo a Locke, han justificado en términos de mandamientos de Dios la apropiación de la tierra de América a los escépticos, tanto en el viejo como en el nuevo mundo.

Existen dos formas importantes por las que el argumento de Locke es distinto del de los otros pensadores mencionados, quienes anclan la doctrina del trabajo, por medio del cultivo y el cercado de terrenos, en el derecho natural más que en el teológico. Si bien Locke incorpora muchos de los argumentos de Purchas, Winthrop y otros defensores de las colonias de Inglaterra en su doctrina de la propiedad, la obra Two Treatises es una articulación original de aquellas ideas, ya que la 
BARBARA ARNEIL

apropiación de la tierra por quien la trabajo es derecho inherente a voluntad de Dios.

Todo hombre tiene una propiedad dentro de su persona... A ella, nadie tiene ningún derecho sino el mismo hombre. La labor de su cuerpo, y el trabajo de sus manos, nos atrevemos a decir, son propiamente de él. Con su labor se mezcla con lo que la naturaleza le ha provisto, produciendo algo que, por ende, se vuelve en parte de su propiedad. ${ }^{73}$

Por lo tanto, Locke concluye que un inglés se puede adueñar de tierra en América no sólo porque está cumpliendo la ley de Dios, como otros sostienen, sino porque tiene el derecho inherente de hacerlo, a través de su trabajo. La justificación de Locke sobre el derecho de Inglaterra al suelo americano se volverá muy importante en el desarrollo de la política india, a medida que las justificaciones teológicas de los puritanos de Nueva Inglaterra del siglo XVII sean superadas por el pensamiento de los republicanos del siglo XVIII basado en los derechos.

La segunda diferencia importante entre la obra Two Treatises y los colonizadores americanos es la creencia implícita de Locke en que los amerindios podían disfrutar de los mismos derechos naturales de los ingleses si cumplían con los mismos criterios básicos de ser trabajadores y racionales, con lo cual no excluye de manera explícita a los amerindios del derecho de la apropiación, sino que aclara las condiciones bajo las cuales podrían disfrutarlo. Deben ser trabajadores y adoptar formas agrarias de trabajo, en oposición a la caza o al pastizal, deben renunciar a sus "formas, modas y conocimientos" del desarrollo de las artes y ciencias, y deben adoptar el oro y el comercio internacional como la base de su comercio con otros. En esencia, deben convertirse en europeos.

El vínculo entre el colonialismo y la teoría de Locke de los derechos naturales tiene tres implicaciones amplias. La primera es el reconoci-

${ }^{73}$ Locke, Two Treatises, op. cit., II, párrafo 27. 
miento de que la teoría de Locke sobre la propiedad debe ser reevaluada no sólo a la luz de Sir Robert Filmer y las intrigas políticas nacionales del día, sino también como una respuesta a las preguntas formuladas por los intereses colonialistas de Shaftesbury. La segunda implicación, hablando en términos más generales, es el reconocimiento del vínculo cercano entre la teoría de los derechos naturales y el colonialismo. Mientras que C. B. Mac Pherson y otros sostienen que la doctrina de Locke es una reflexión del "individualismo posesivo" de los inicios del capitalismo, realidad histórica conflictiva de la Inglaterra del siglo XVII, cuya problematicidad teórica será superada por una conexión muy cercana y tangible entre Locke y la plantación americana. ${ }^{74}$ Finalmente, la doctrina de los derechos naturales, que supone en sí la trascendencia del estado de naturaleza por la sociedad civil deja al amerindio, descrito en la obra Two Treatises, en una situación complicada, imposible, teórica y posteriormente históricamente. Si los conceptos trabajo y racionalidad, definidos por Locke para incluir las artes, la ciencia y el dinero europeos, deben ser el precio para la ciudadanía, la elección es clara. El amerindio puede permanecer en el estado de la naturaleza y renunciar esencialmente a sus derechos a la tierra o unirse a la sociedad civil y renunciar a sí mismo. La conciliación de la teoría liberal con los reclamos aborígenes sobre ellos mismos y su tierra continúa saturada de esta dicotomía subyacente entre el estado de naturaleza y la sociedad civil, y de la implícita necesidad teórica de que los reclamos comprendidos en el primer elemento sean asimilados en el segundo, a través de la propiedad privada y la razón.

${ }^{74}$ C. B. Mac Pherson, The Political Theory of Possessive Individualism, 1962, Oxford. Para las críticas, ver Peter Laslett, "Market Society and Political Theory Review of Mac Pherson", Historical Journal, VII, 1964; Isaiah Berlin, "Hobbes, Locke and Professor Mac Pherson", Political Quarterly, XXXv, 1964. 